\title{
Fragmentation Pathways of Cationized, Saturated, Short-chain Triacylglycerols: Lithiated and Sodiated Tripropanoyl- and Trihexanoylglycerol - Supplementary Material -1, graphics
}

\author{
J. Stuart Grossert ${ }^{1}$, Jeremy E. Melanson ${ }^{2}$, Louis Ramaley ${ }^{1}$ \\ ${ }^{1}$ Department of Chemistry, Dalhousie University, Halifax, NS, Canada B3H 4R2 \\ ${ }^{2}$ Measurement Science and Standards, National Research Council Canada, 1200 Montreal Rd., \\ Ottawa, ON, Canada K1A 0R6
}

\section{Contents: Figures S1 - S14}

Figure S1. The structure and nomenclature of triacylglycerols

Figure S2. Product ion spectra from collisional activation of lithiated tripropanoylglycerol $\left(1.0 \times 10^{-4} \mathrm{M}\right.$ lithium trifluoroacetate $+5.0 \times 10^{-6} \mathrm{M}$ tripropanoylglycerol), acquired at a collision gas pressure of $6.0 \times 10^{-4}$ $\mathrm{mBar}$ (instrument value). The source cone voltage was set to $20 \mathrm{~V}$ and the collision energies ranged from $3 \mathrm{eV}$ to $21 \mathrm{eV}$ in the laboratory frame.

Figure S3. Computed structures with relative free energies for a selection of conformers of $[\mathrm{PrPrPr}+\mathrm{Li}]+$; Structures A1, A3 and A4 were found to be needed in Pathway 13/31, Pathway 21/23 and Pathway 12/32, respectively.

Figure S4. Fragmentation of $\left[\mathrm{PrPrPr}+\mathrm{Li}^{+}\right.$from collisionally-induced dissociation, with displacement of a lithiated $s n-3 / 1$ substituent by an $s n-1 / 3$ carbonyl group (Pathway 13/31), showing (a) a mechanistic outline, where $\mathrm{R}_{1}=\mathrm{R}_{2}=\mathrm{R}_{3}=\mathrm{C}_{2} \mathrm{H}_{5}$ and $\mathrm{R}_{1}{ }^{\prime}=\mathrm{CH}_{3}$, (b) a detailed, computed reaction pathway, and (c) computed energetics for the pathway. In (b) the $s n-1$ carbon atom in the glycerol chains is shaded black while the sn-3 carbon atom is white. A pathway and energetics for the formation of 6P3' is outlined in Figure S7.

Figure S5. Fragmentation of $[\mathrm{PrPrPr}+\mathrm{Li}]^{+}$from collision-induced dissociation, with displacement of a lithiated $s n-2$ substituent by an $s n-1 / 3$ carbonyl group (Pathway 21/23), showing (a) a mechanistic outline, where $\mathrm{R}_{1}=\mathrm{R}_{2}=\mathrm{R}_{3}=\mathrm{C}_{2} \mathrm{H}_{5}$ and $\mathrm{R}_{1}{ }^{\prime}=\mathrm{CH}_{3}$, (b) a detailed, computed reaction pathway, and (c) computed energetics for the pathway. In (b) the $s n-1$ carbon atom in the glycerol chains is shaded black while the sn3 carbon atom is white. Formation of $\mathbf{5 P 3}$ ' is outlined in Figure S7.

Figure S6. Fragmentation of $[\mathrm{PrPrPr}+\mathrm{Li}]^{+}$from collision-induced dissociation, with displacement of a lithiated sn-2 substituent by an sn-1/3 carbonyl group (Pathway 12/32), showing (a) a mechanistic outline, where $\mathrm{R}_{1}=\mathrm{R}_{2}=\mathrm{R}_{3}=\mathrm{C}_{2} \mathrm{H}_{5}$ and $\mathrm{R}_{1}{ }^{\prime}=\mathrm{CH}_{3}$, (b) a detailed, computed reaction pathway, and (c) computed energetics for the pathway. In (b) the $s n-1$ carbon atom in the glycerol chains is shaded black while the sn3 carbon atom is white. Formation of $\mathbf{5 P 6}$ ' is outlined in Figure S7.

Figure S7. Computed structures and free energies for the formation of gamma-lactones and propanoic acid from: (a) Pathway 13/31 (see Figure 2), (b) Pathway 21/23 (see Figure 3) and (c) Pathway 12/32 (see Figure S6), (d) structures for the interconversion of ions between Pathways 13/31 and 21/23 or $12 / 32$, and (e) structures of lactones having different coordination sites. Energy values are free energies $\left(\mathrm{kJ} \mathrm{mol}^{-1}\right)$, relative to Structure $\mathbf{A} \mathbf{0}$.

Figure S8.(a) Breakdown Curves, where $\bullet=[\mathrm{TAG}+\mathrm{Na}]^{+}, \quad \boldsymbol{\Delta}=[\mathrm{TAG}+\mathrm{Na}-\mathrm{PrH}]^{+}, \quad \mathbf{m}=[\mathrm{TAG}+\mathrm{Na}-$ $\mathrm{PrM}^{+}, \boldsymbol{\nabla}=m / z 57, \bullet=m / z 23$, cone voltage $=20 \mathrm{~V}$. (b) Product ion spectra from collisional activation of sodiated tripropanoylglycerol $\left(1.0 \times 10^{-4} \mathrm{M}\right.$ sodium trifluoroacetate $+5.0 \times 10^{-6} \mathrm{M}$ tripropanoylglycerol), acquired at a collision gas pressure of $8.0 \times 10^{-4} \mathrm{mBar}$ (instrument value). The source cone voltage was set to $20 \mathrm{~V}$ and the collision energies ranged from $3 \mathrm{eV}$ to $21 \mathrm{eV}$ in the laboratory frame. 
Figure S9. Fragmentation of $[\mathrm{PrPrPr}+\mathrm{Na}]^{+}$after collisionally-induced dissociation, with displacement of a sodiated $s n-1 / 3$ substituent by an $s n-2$ carbonyl group (Pathway 12/32). Energy values are computed free energies $\left(\mathrm{kJ} \mathrm{mol}^{-1}\right)$, relative to $\mathrm{Na0}$.

Figure S10. Formation of $m / z 57$ from collisional activation of $m / z 187$, selected after in-source fragmentation (pseudo $\mathrm{MS}^{3}$ on lithiated tripropanoylglycerol), showing a reaction pathway, mass spectrum and computed energetics where energy values are free energies $\left(\mathrm{kJ} \mathrm{mol}^{-1}\right)$, relative to Structure $\mathbf{A 0}$.

Figure S11. Product ion spectra from collisional activation of $\mathrm{m} / \mathrm{z} 193$, selected after in-source fragmentation (pseudo $\mathrm{MS}^{3}$ on lithiated tripropanoylglycerol), acquired at a collision gas pressure of $6.0 \times 10^{-}$ ${ }^{4} \mathrm{mBar}$ (instrument value). The source cone voltage was set to $30 \mathrm{~V}$ and the collision energies ranged from $3 \mathrm{eV}$ to $13 \mathrm{eV}$ in the laboratory frame.

Figure S12. Energetically plausible, computed fragmentation pathways for three minor ions (pseudo $\mathrm{MS}^{3}$ ) observed from $m / z$ 193, leading to ions at (a) $m / z$ 137, (b) $m / z 63$ and (c) $m / z 51$.

Figure S13. Product ion spectra $\left(\mathrm{MS}^{2}\right)$ from collisional activation of (a) lithiated trihexanoylglycerol $\left(8.0 \times 10^{-6} \mathrm{M}\right.$ with $1.0 \times 10^{-4} \mathrm{M}$ lithium trifluoroacetate), and $(\underline{\mathbf{b}})$ sodiated trihexanoylglycerol $\left(8.0 \times 10^{-6} \mathrm{M}\right.$ with $1.0 \times 10^{-4} \mathrm{M}$ sodium trifluoroacetate) acquired at a collision gas pressure of $6.0 \mathrm{e}^{-4} \mathrm{mBar}$ (instrument value). The source cone was set at $20 \mathrm{~V}$ and the collision energies ranged from $3 \mathrm{eV}$ to 21 $\mathrm{eV}$ in the laboratory frame.

Figure S14. Product ion spectra from collisional activation of (a) $m / z 277$ and (b) $m / z 271$, selected after in-source fragmentation (pseudo $\mathrm{MS}^{3}$ on lithiated trihexanoylglycerol) of $\mathrm{m} / \mathrm{z} 393\left[\mathrm{C}_{21} \mathrm{H}_{38} \mathrm{O}_{6}+\mathrm{Li}\right]^{+}$, acquired at a collision gas pressure of $6.0 \times 10^{-4} \mathrm{mBar}$ (instrument value). The collision energies are in the laboratory frame.

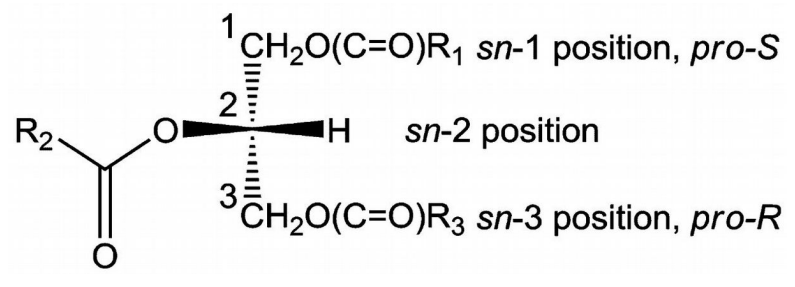

Descriptors of TAGs traditionally have 1- or 2-letter abbreviations for the acyl chains, such as POS, where $\mathrm{P}=$ palmitoyl $(s n-1), \mathrm{O}=$ oleyl $(s n-2)$ and $\mathrm{S}=$ steroyl $(s n-3)$. Two TAGs were studied in this work, $\operatorname{Pr} \operatorname{Pr} P r(\mathrm{Pr}=$ propanoyl) and $\mathrm{HxHxHx}(\mathrm{Hx}=$ hexanoyl).

Alternatively, a more recent nomenclature system (LipidMaps) which covers a full range of lipids can be used. In this case PrPrPr would be referred to as TG(3:0/3:0/3:0) and HxHxHx as TG(6:0/6:0/6:0).

Figure S1. The structure and nomenclature of triacylglycerols 


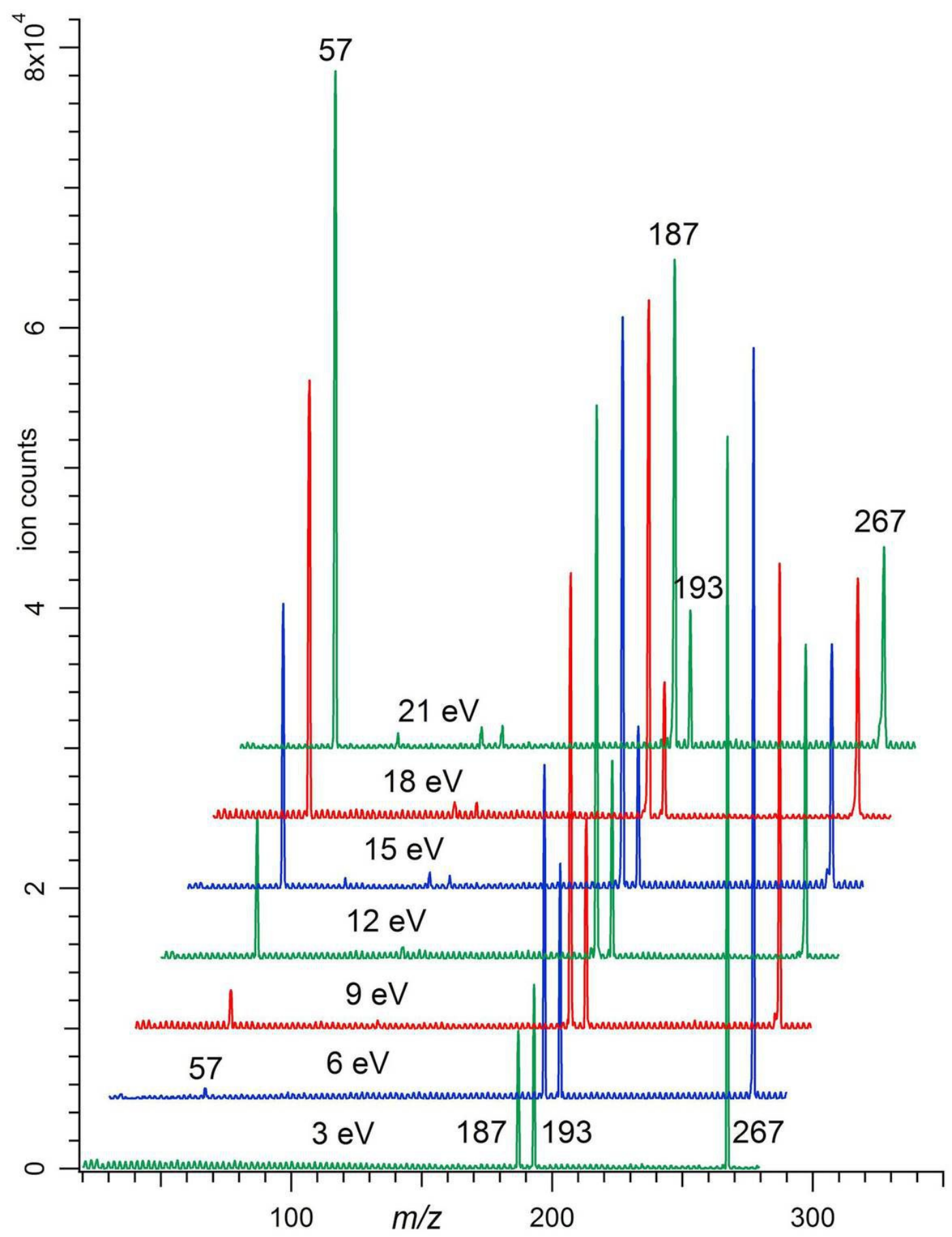

Figure S2. Product ion spectra from collisional activation of lithiated tripropanoylglycerol $\left(1.0 \times 10^{-4} \mathrm{M}\right.$ lithium trifluoroacetate $+5.0 \times 10^{-6} \mathrm{M}$ tripropanoylglycerol), acquired at a collision gas pressure of $6.0 \times 10^{-4} \mathrm{mBar}$ (instrument value). The source cone voltage was set to $20 \mathrm{~V}$ and the collision energies ranged from $3 \mathrm{eV}$ to $21 \mathrm{eV}$ in the laboratory frame. 

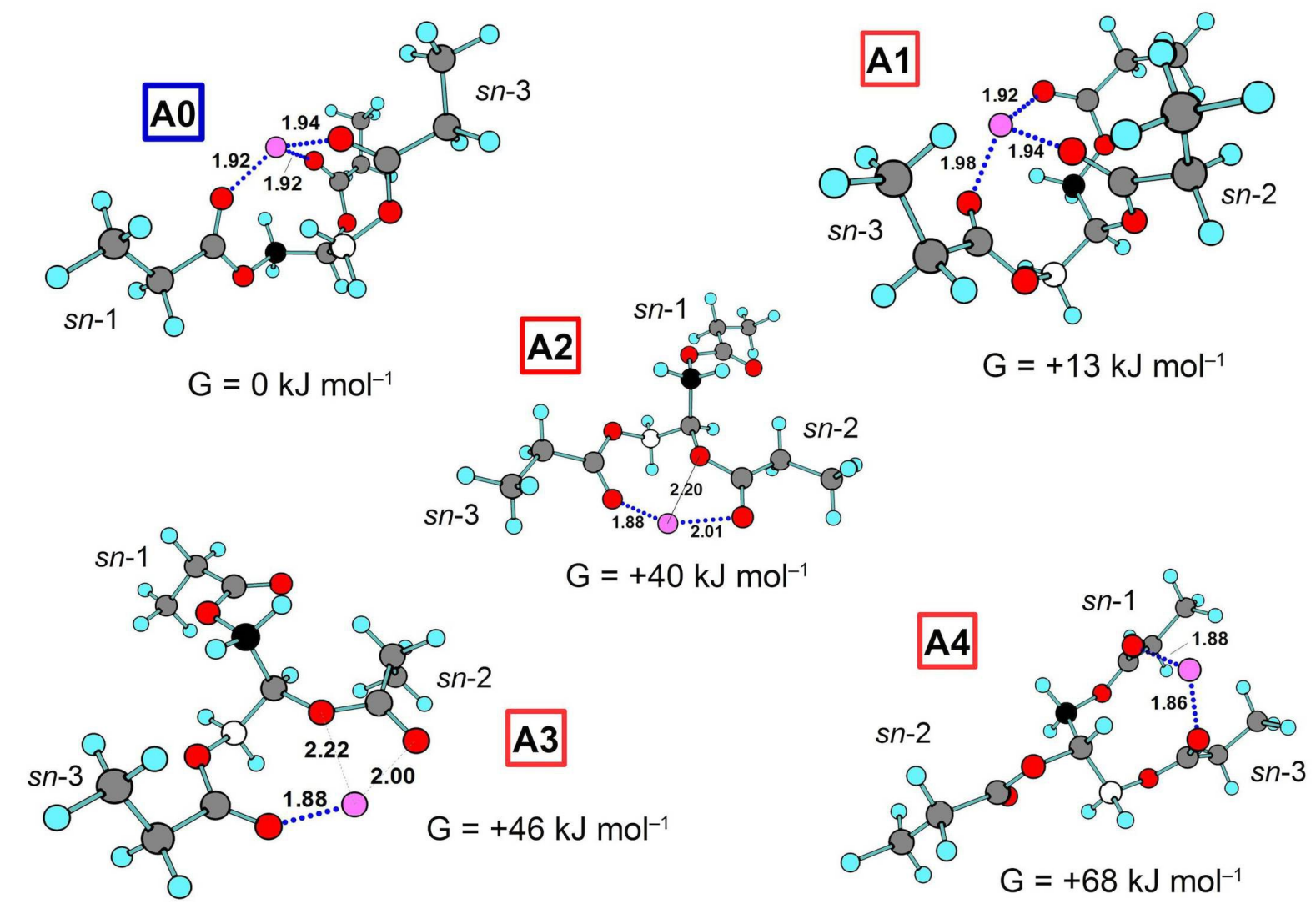

Figure S3. Computed structures with relative free energies for a selection of conformers of $[\operatorname{PrPrPr}+$ $\mathrm{Li}^{+}$; Structures A1, A3 and A4 were found to be needed in Pathway 13/31, Pathway 21/23 and Pathway 12/32, respectively. 


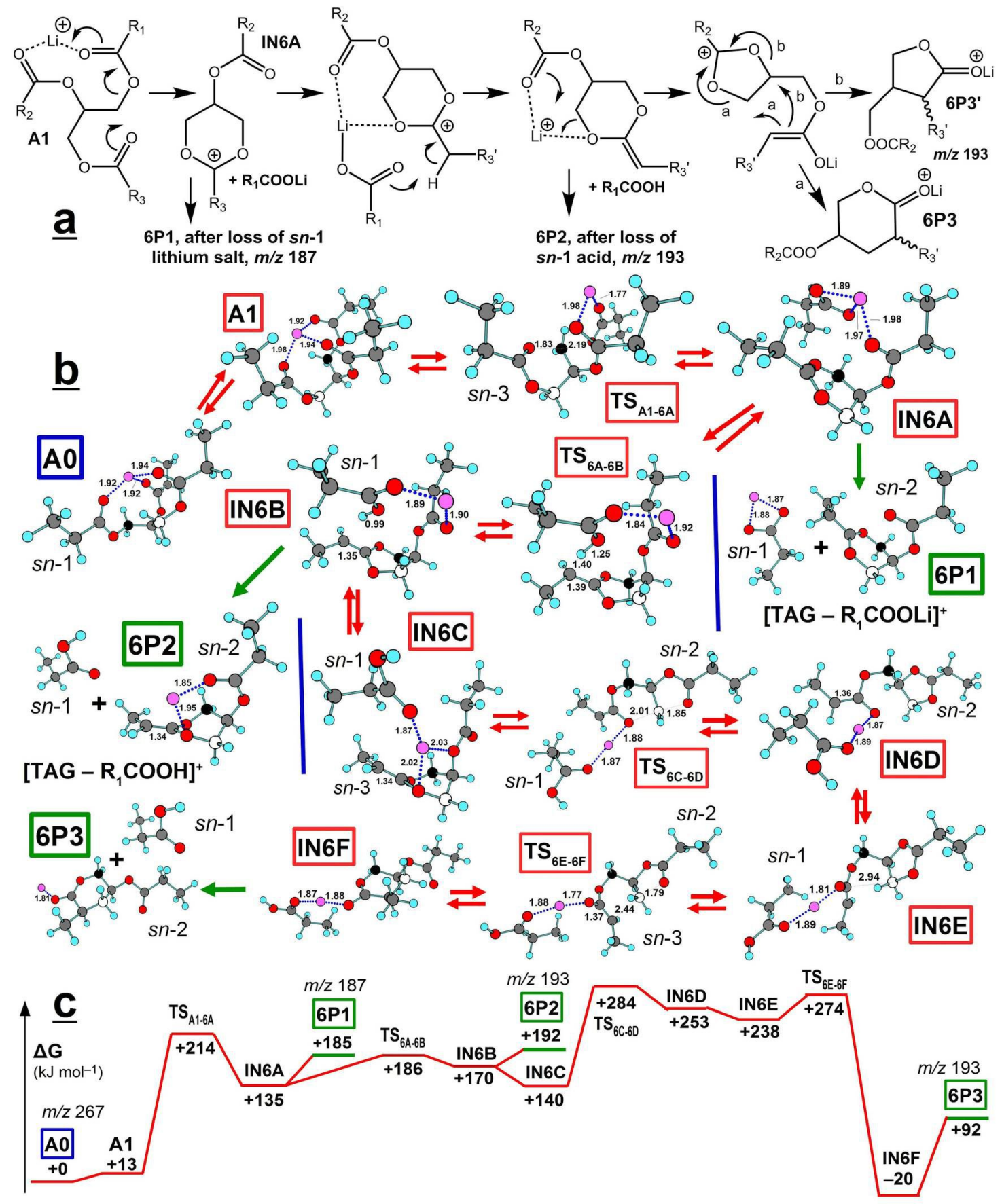

Figure S4. Fragmentation of $\left[\mathrm{PrPrPr}+\mathrm{Li}^{+}\right.$from collisionally-induced dissociation, with displacement of a lithiated $s n-3 / 1$ substituent by an $s n-1 / 3$ carbonyl group (Pathway 13/31), showing (a) a mechanistic outline, where $\mathrm{R}_{1}=\mathrm{R}_{2}=\mathrm{R}_{3}=\mathrm{C}_{2} \mathrm{H}_{5}$ and $\mathrm{R}_{3}{ }^{\prime}=\mathrm{CH}_{3}$, (b) a detailed, computed reaction pathway, and (c) computed energetics for the pathway. A pathway and energetics for the formation of 6P3' are outlined in Figure S7. 

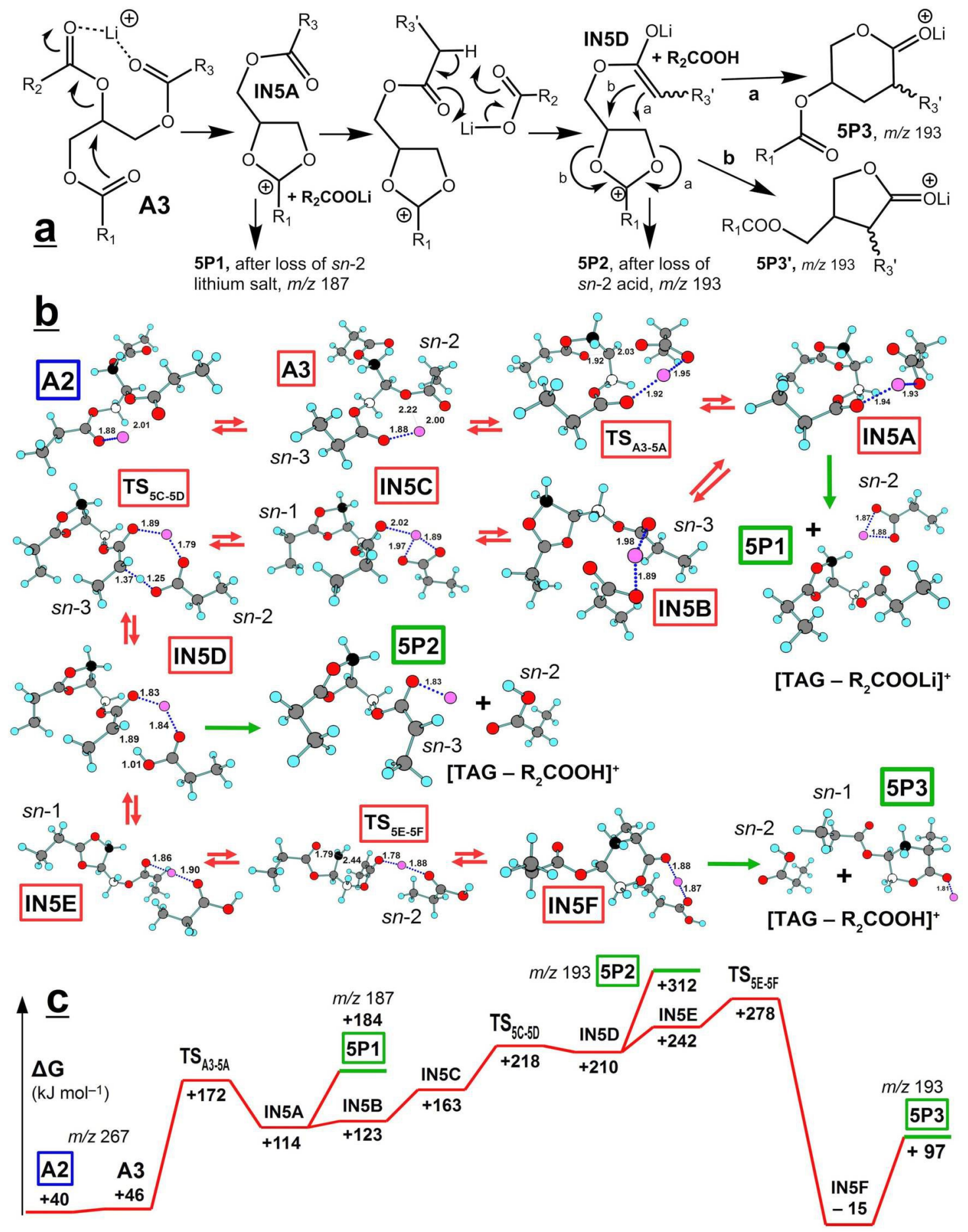

Figure S5. Fragmentation of $[\mathrm{PrPrPr}+\mathrm{Li}]^{+}$from collision-induced dissociation, with displacement of a lithiated sn-2 substituent by an sn-1/3 carbonyl group (Pathway 21/23), showing (a) a mechanistic outline, where $R_{1}=R_{2}=R_{3}=C_{2} H_{5}$ and $R_{1}{ }^{\prime}=C_{3}$, (b) a detailed, computed reaction pathway, and (c) computed

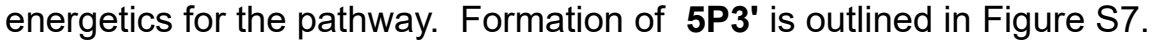




\section{Product ion formation via Pathway 12/32, Figure S6}

From $\mathbf{A} \mathbf{0}$ and $\mathbf{A 4}$, a saddle point led to the ion-neutral complex IN5G which could fragment to give a dioxolanium cation, $\mathbf{5 P 4}$, plus the lithiated salt from the $s n-1$ chain. The substituent adjacent to the charge site in $\mathbf{5 P 4}$ is part of the sn-2 chain; thus, while $5 \mathrm{P} 4$ and $5 \mathrm{P} 1$ are equivalent in the present work, would not be the case for a TAG having a lower level of symmetry. The computed conformations of these two cations were different, which resulted in them having different computed energies.

Ion neutral IN5G was interconvertible with IN5H from which proton abstraction could occur as before, leading to the ion-neutral IN5I, from which two further pathways were possible. The lithiated enol, 5P5 is structurally similar to 5P2 (different chains on the dioxolane ring), but the two also differ in conformations and computed energies. The details of the formation of the gamma-lactone 5P6' are presented in Figure S7. 

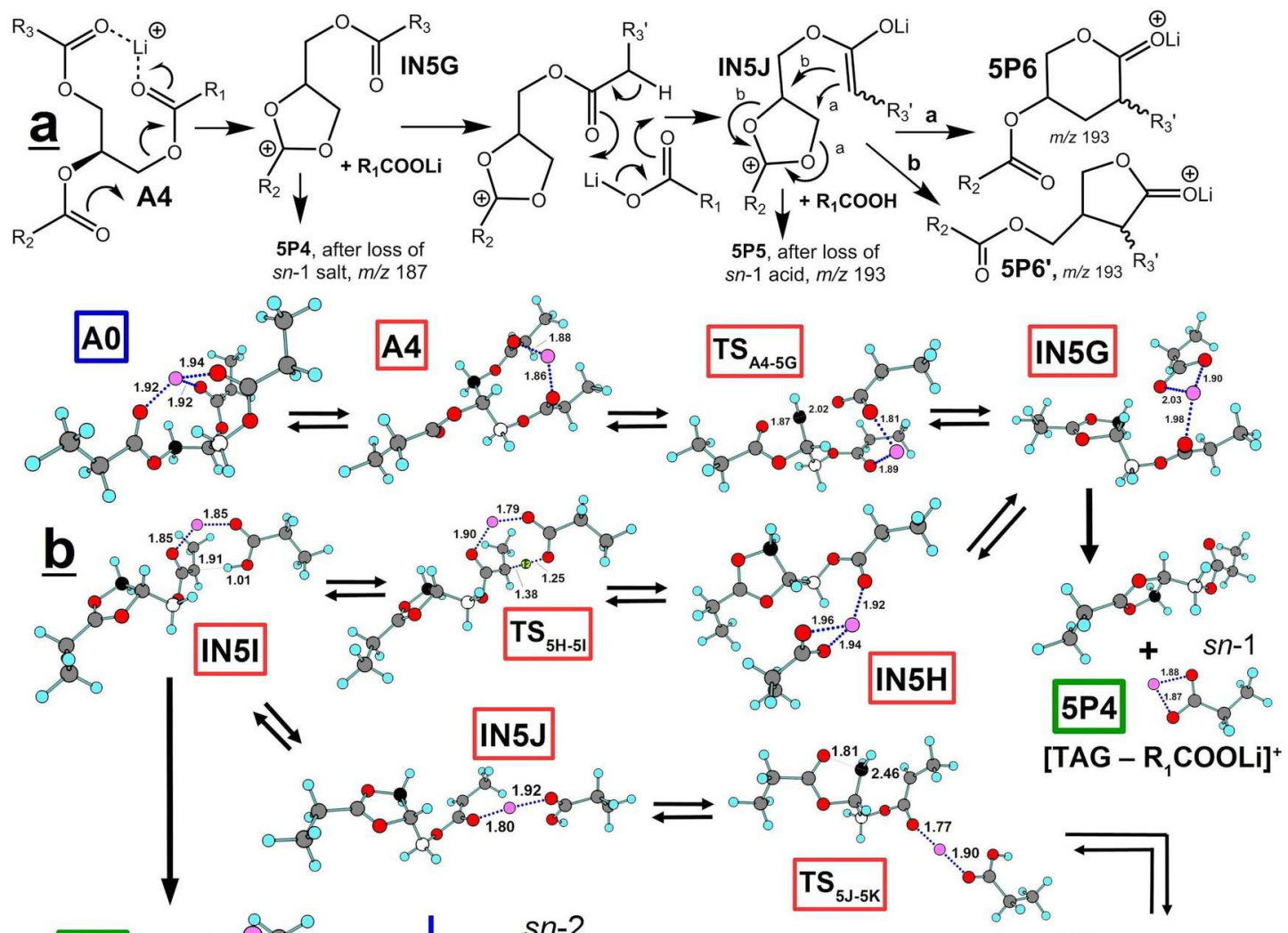

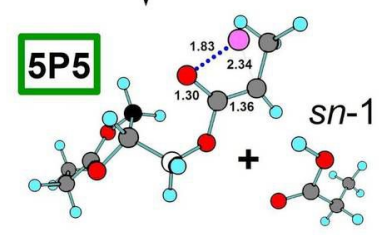

[TAG $\left.-\mathrm{R}_{1} \mathrm{COOH}\right]^{+}$

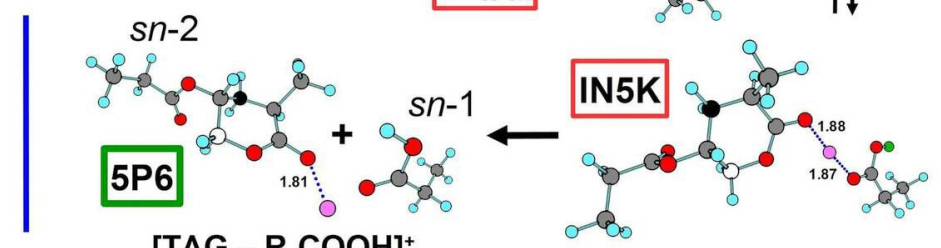

[TAG $\left.-\mathrm{R}_{1} \mathrm{COOH}\right]^{+}$

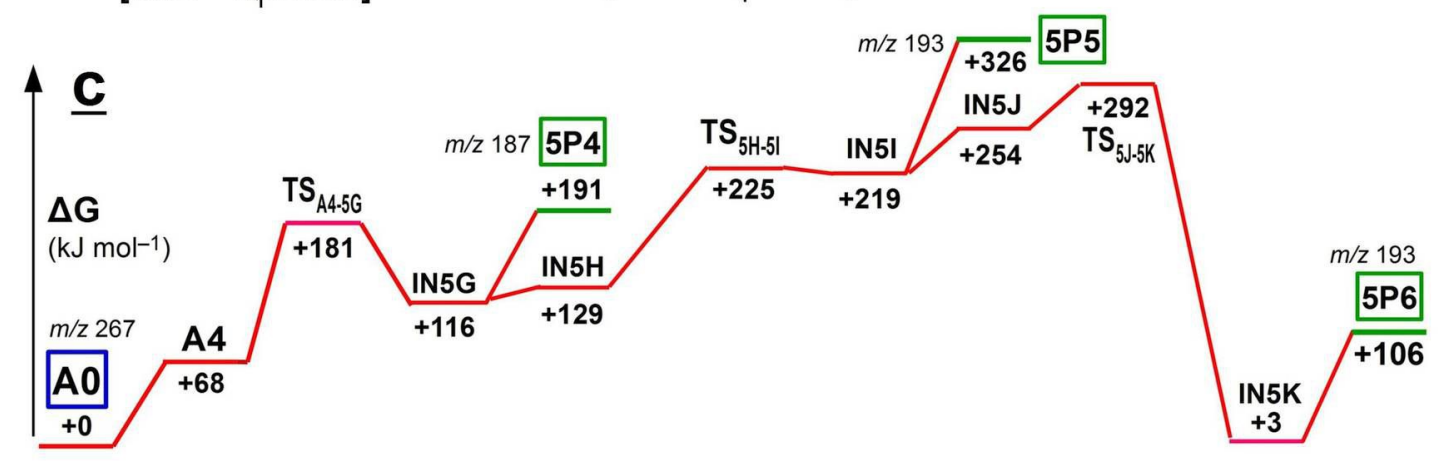

Figure S6. Fragmentation of $\left[\mathrm{PrPrPr}+\mathrm{Li}^{+}\right.$from collision-induced dissociation, with displacement of a lithiated sn-2 substituent by an sn-1/3 carbonyl group (Pathway 12/32), showing (a) a mechanistic outline, where $\mathrm{R}_{1}=\mathrm{R}_{2}=\mathrm{R}_{3}=\mathrm{C}_{2} \mathrm{H}_{5}$ and $\mathrm{R}_{1}{ }^{\prime}=\mathrm{CH}_{3}$, (b) a detailed, computed reaction pathway, and (c) computed energetics for the pathway. Formation of $\mathbf{5 P 6}$ ' is outlined in Figure S7. 

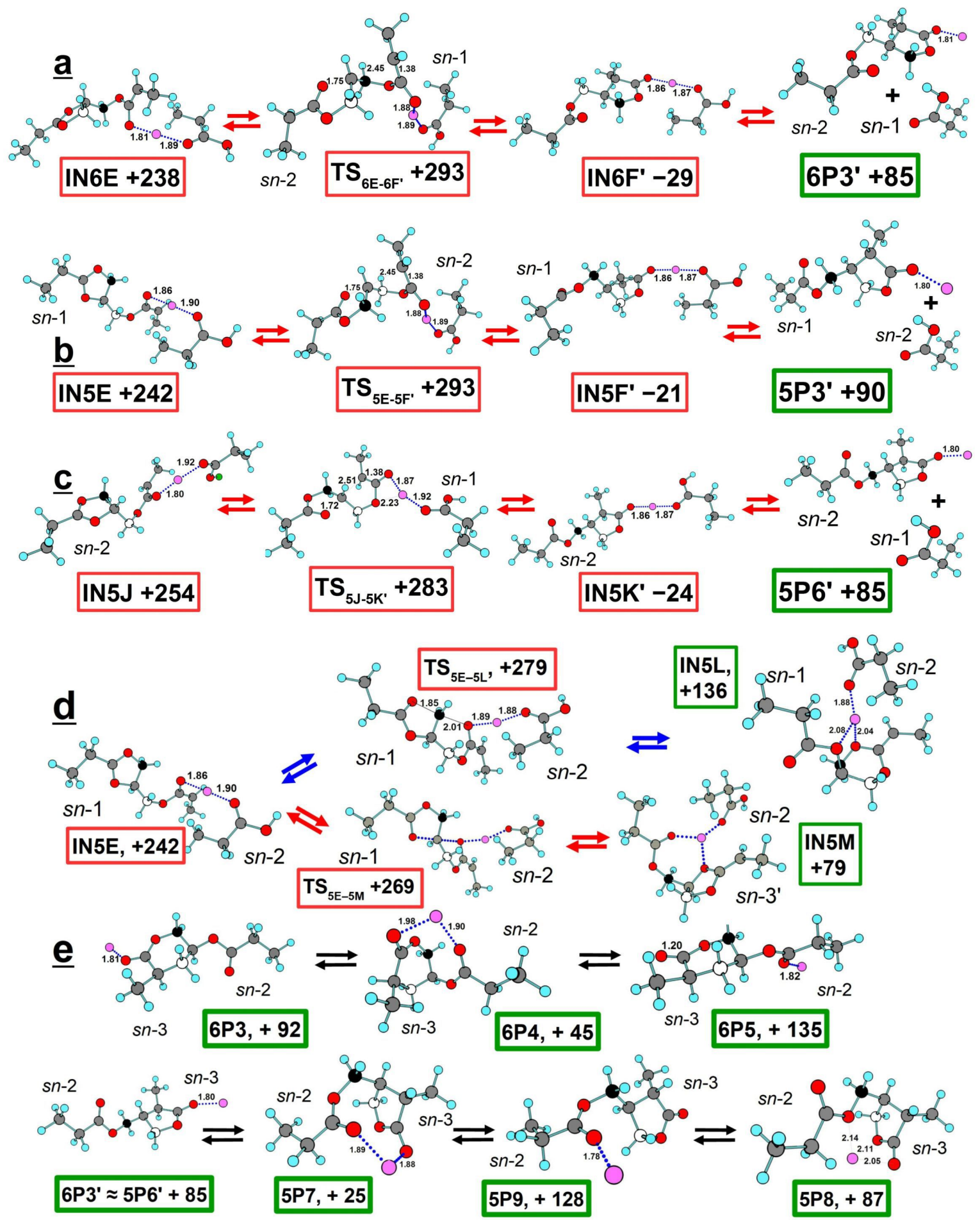

Figure S7. Computed structures and free energies for rearrangement processes from: (a) Pathway 13/31 (see Figure S4), (b) Pathway 21/23 (see Figure 3) and (c) Pathway 12/32 (see Figure S6), (d) the interconversion of ions between Pathways 13/31 and 21/23 or 12/32, and (e) structures of lactones having different coordination sites from Pathways 21/23 and 12/32. Energy values are free energies $\left(\mathrm{kJ} \mathrm{mol}^{-1}\right)$, relative to Structure $\mathbf{A} \mathbf{0}$. 

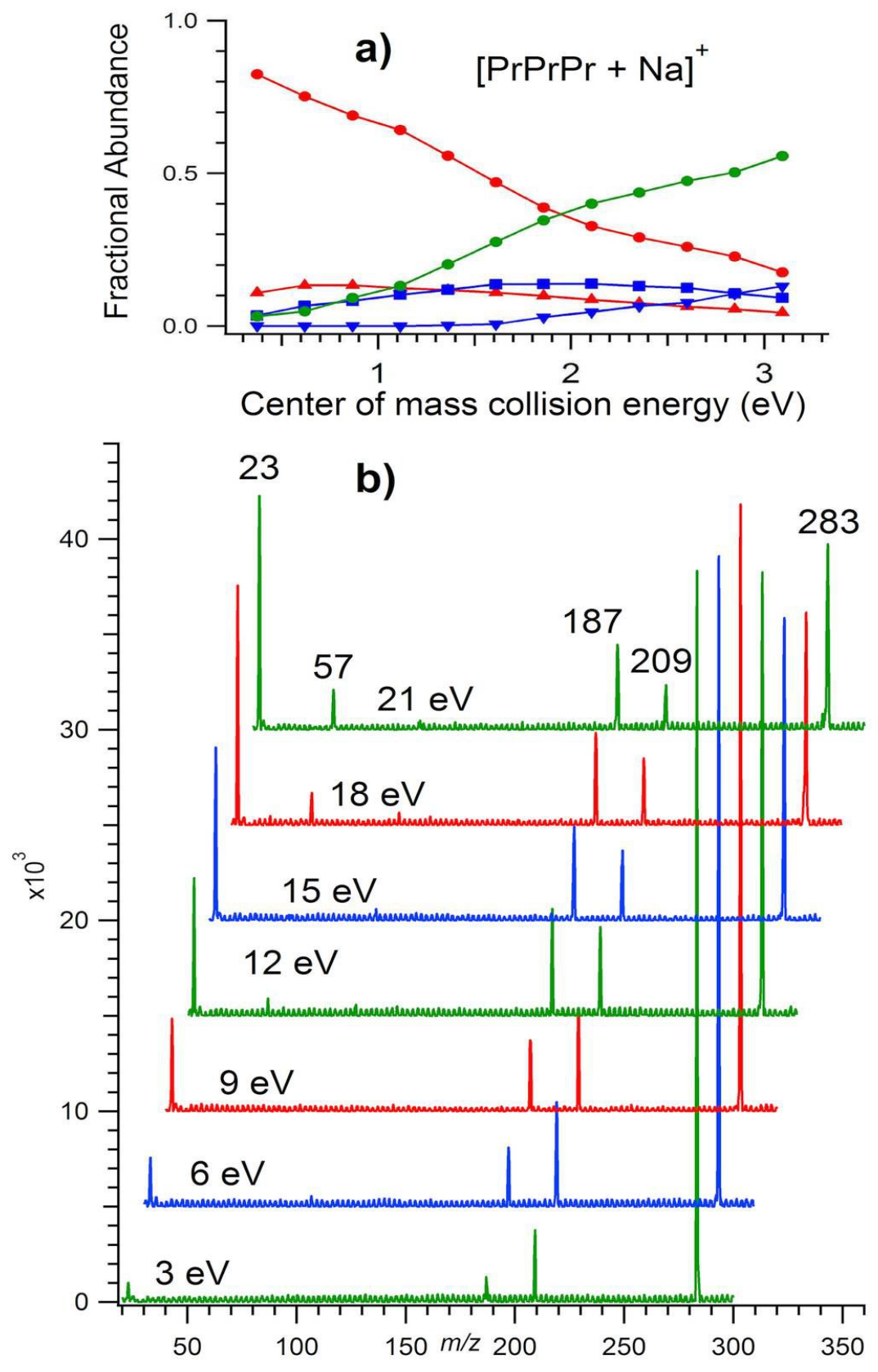

Figure S8.(a) Breakdown Curves, where $\bullet=\left[\mathrm{TAG}+\mathrm{Na}^{+}, \quad \boldsymbol{\Delta}=[\mathrm{TAG}+\mathrm{Na}-\mathrm{PrH}]^{+}, \quad=[\mathrm{TAG}+\mathrm{Na}-\right.$ $\mathrm{PrM}^{+}, \boldsymbol{\nabla}=m / z 57, \bullet=m / z 23$, cone voltage $=20 \mathrm{~V}$. (b) Product ion spectra from collisional activation of sodiated tripropanoylglycerol $\left(1.0 \times 10^{-4} \mathrm{M}\right.$ sodium trifluoroacetate $+5.0 \times 10^{-6} \mathrm{M}$ tripropanoylglycerol), acquired at a collision gas pressure of $8.0 \times 10^{-4} \mathrm{mBar}$ (instrument value). The source cone voltage was set to $20 \mathrm{~V}$ and the collision energies ranged from $3 \mathrm{eV}$ to $21 \mathrm{eV}$ in the laboratory frame. 

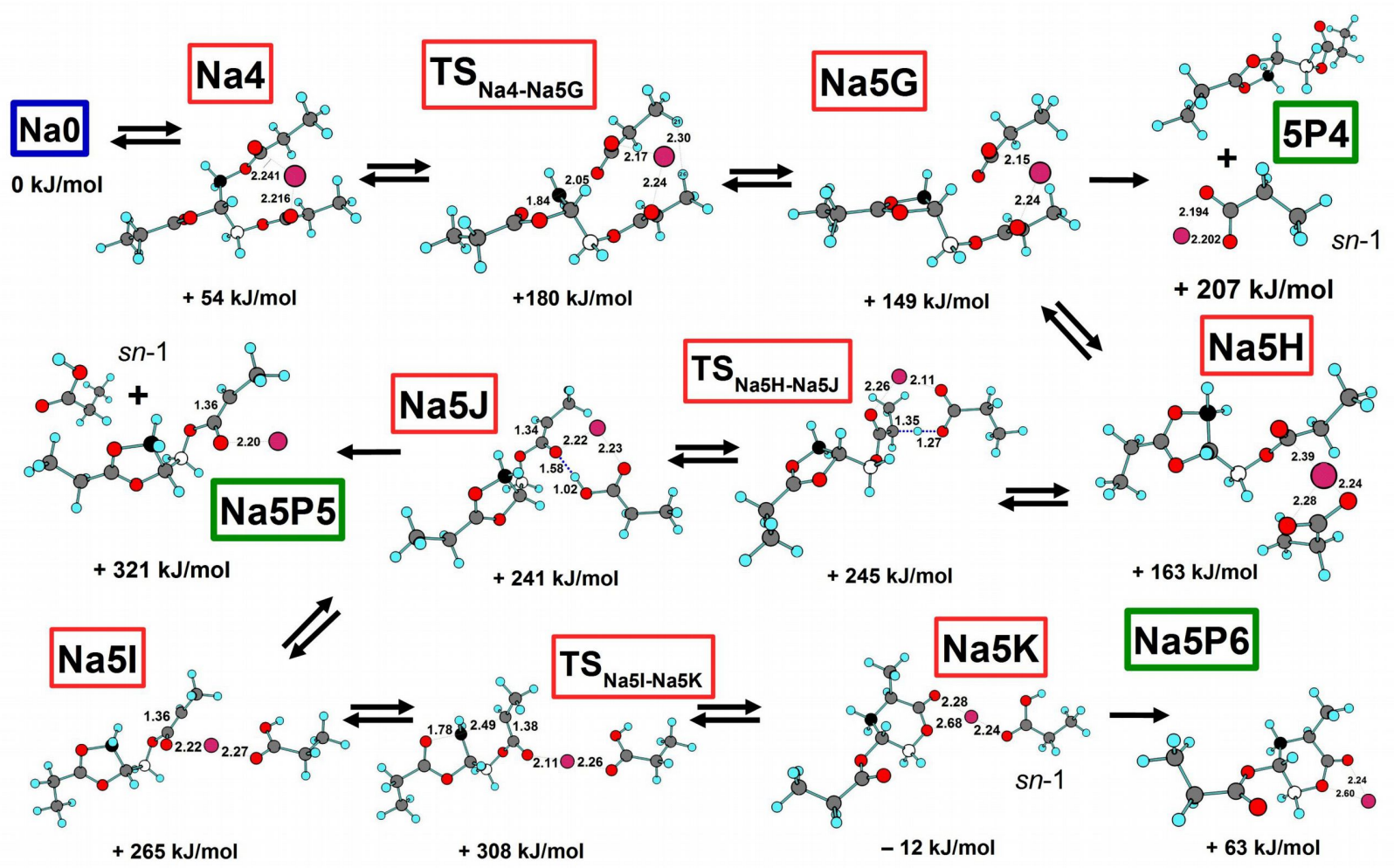

Figure S9. Fragmentation of $[\mathrm{PrPrPr}+\mathrm{Na}]^{+}$after collisionally-induced dissociation, with displacement of a sodiated $s n-1 / 3$ substituent by an $s n-2$ carbonyl group (Pathway 12/32). Energy values are computed free energies $\left(\mathrm{kJ} \mathrm{mol}^{-1}\right)$, relative to $\mathrm{Na}$. 
12/16 Grossert, Melanson, Ramaley, JASMS 2019, Supp. 1, graphics

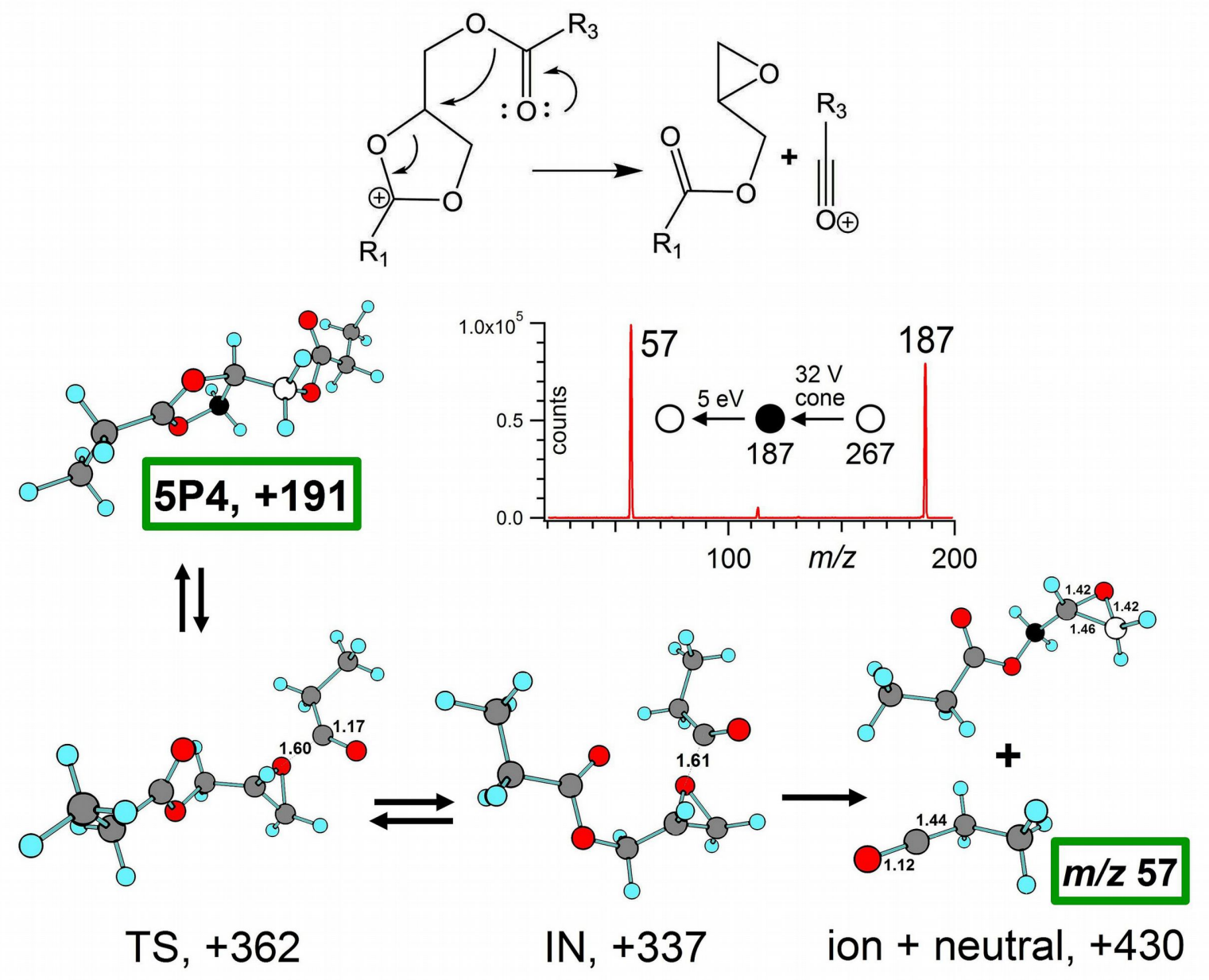

Figure S10. Formation of $\mathrm{m} / \mathrm{z} 57$ from collisional activation of $\mathrm{m} / \mathrm{z} 187$, selected after in-source fragmentation (pseudo $\mathrm{MS}^{3}$ on lithiated tripropanoylglycerol), showing a reaction pathway, mass spectrum and computed energetics where energy values are free energies $\left(\mathrm{kJ} \mathrm{mol}^{-1}\right)$, relative to Structure A0. 


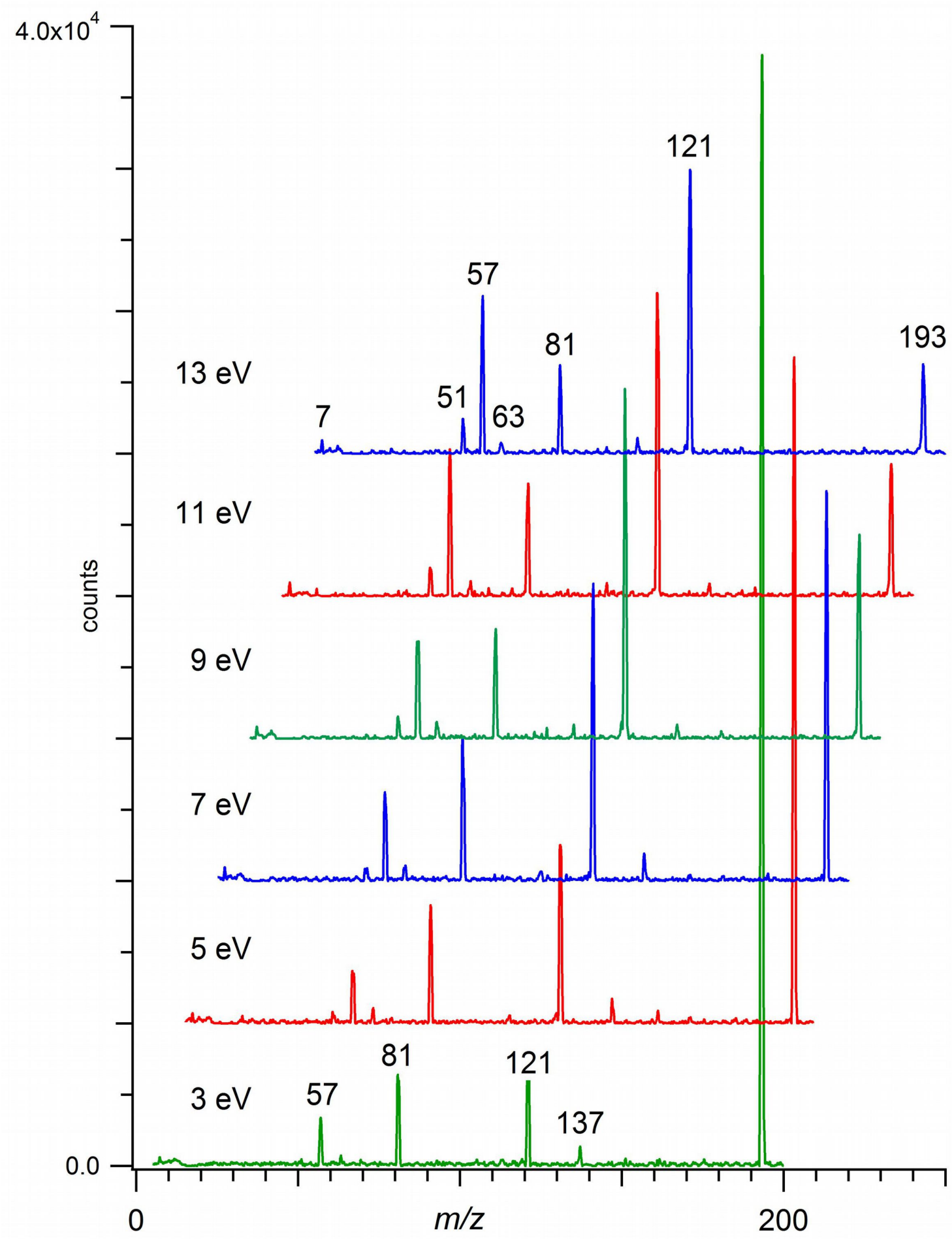

Figure S11. Product ion spectra from collisional activation of $m / z 193$, selected after in-source fragmentation (pseudo $\mathrm{MS}^{3}$ on lithiated tripropanoylglycerol), acquired at a collision gas pressure of $6.0 \times 10^{-4} \mathrm{mBar}$ (instrument value). The source cone voltage was set to $30 \mathrm{~V}$ and the collision energies ranged from $3 \mathrm{eV}$ to $13 \mathrm{eV}$ in the laboratory frame. 

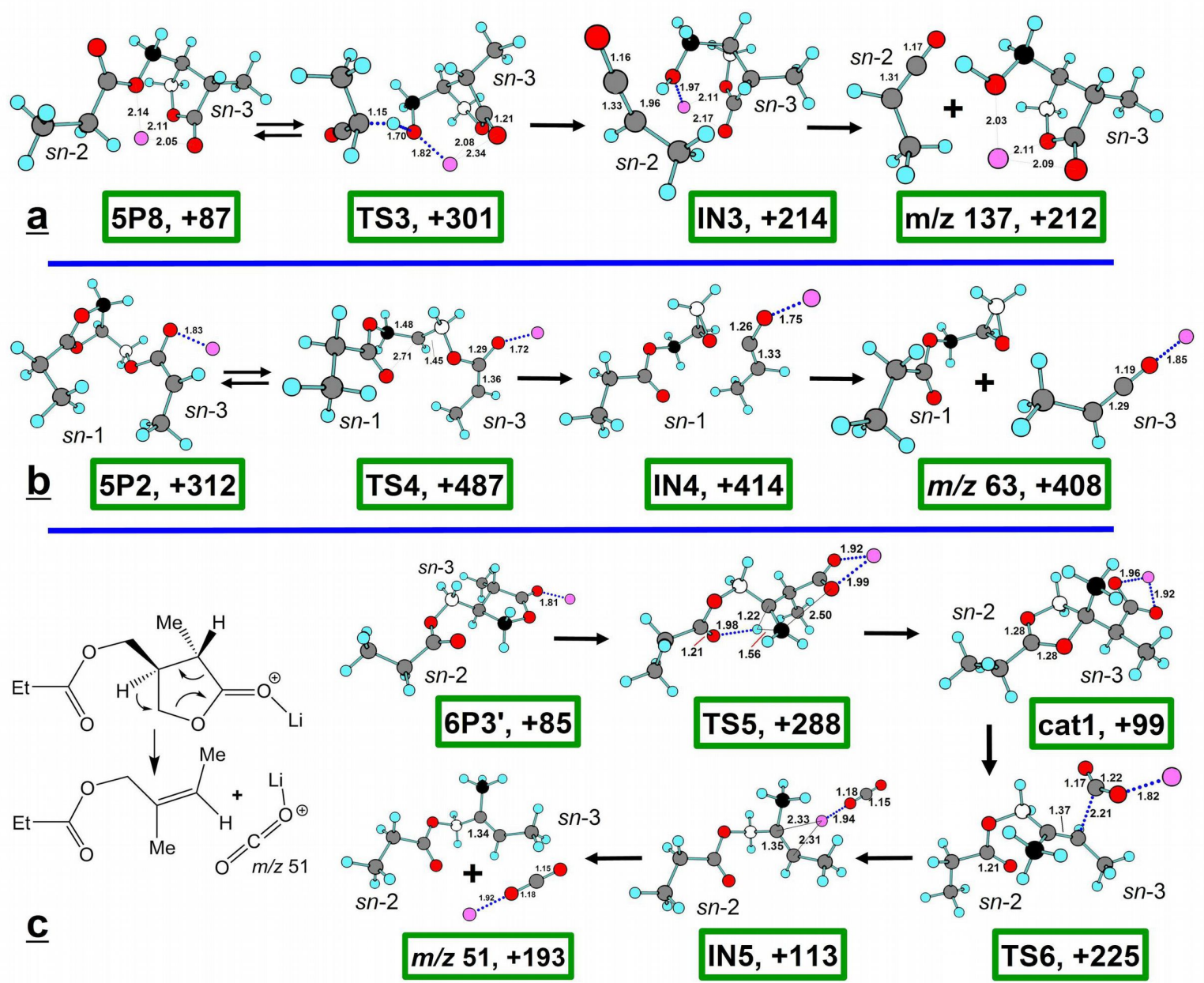

Figure S12. Energetically plausible, computed fragmentation pathways for three minor ions (pseudo $\mathrm{MS}^{3}$ on $\left[\mathrm{PrPrPr}+\mathrm{Li}^{+}\right.$) observed from $\mathrm{m} / \mathrm{z}$ 193, leading to ions at (a) $\mathrm{m} / \mathrm{z}$ 137, (b) $\mathrm{m} / \mathrm{z} 63$ and (c) $\mathrm{m} / \mathrm{z}$ 51. 


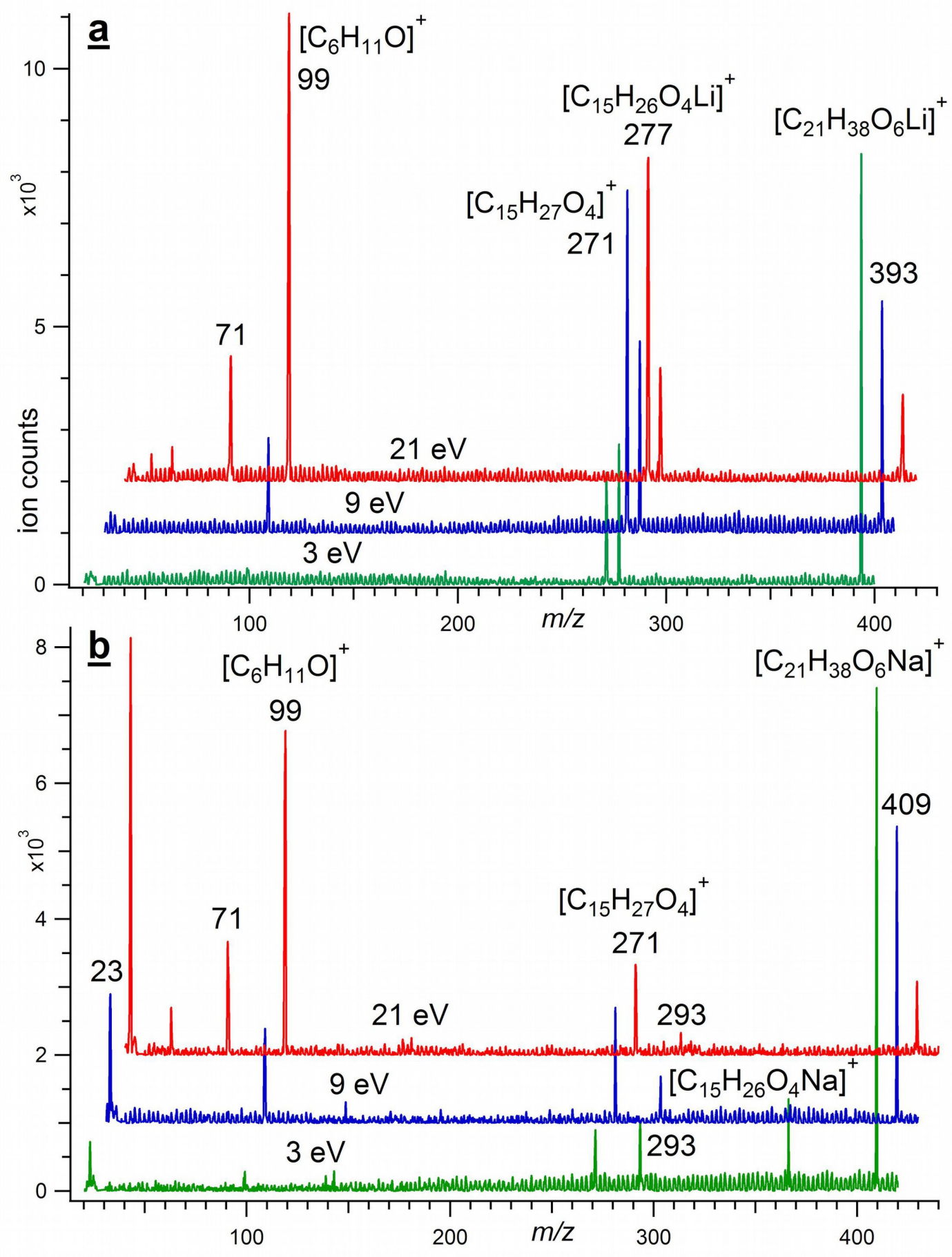

Figure S13. Product ion spectra $\left(\mathrm{MS}^{2}\right)$ from collisional activation of (a) lithiated trihexanoylglycerol $\left(8.0 \times 10^{-6} \mathrm{M}\right.$ with $1.0 \times 10^{-4} \mathrm{M}$ lithium trifluoroacetate), and $(\underline{\mathbf{b}})$ sodiated trihexanoylglycerol $\left(8.0 \times 10^{-6} \mathrm{M}\right.$ with $1.0 \times 10^{-4} \mathrm{M}$ sodium trifluoroacetate) acquired at a collision gas pressure of $6.0 \mathrm{e}^{-4} \mathrm{mBar}$ (instrument value). The source cone was set at $20 \mathrm{~V}$ and the collision energies ranged from $3 \mathrm{eV}$ to 21 $\mathrm{eV}$ in the laboratory frame. 


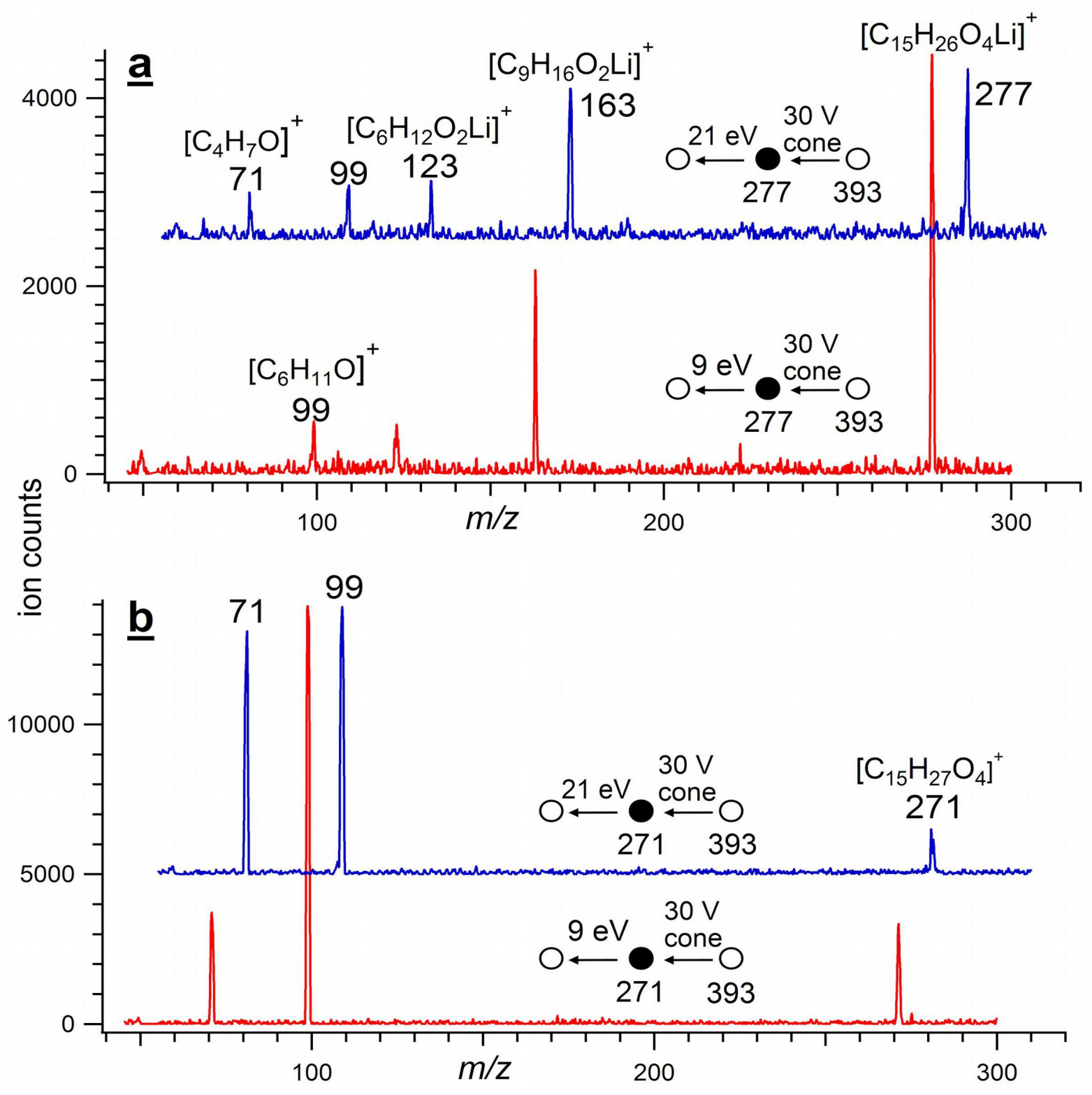

Figure S14. Product ion spectra from collisional activation of (a) $m / z 277$ and (b) $m / z 271$, selected after in-source fragmentation (pseudo $\mathrm{MS}^{3}$ on lithiated trihexanoylglycerol) of $\mathrm{m} / \mathrm{z} 393\left[\mathrm{C}_{21} \mathrm{H}_{38} \mathrm{O}_{6}+\mathrm{Li}\right]^{+}$, acquired at a collision gas pressure of $6.0 \times 10^{-4} \mathrm{mBar}$ (instrument value). The collision energies are in the laboratory frame. 